\title{
ERP evidence for own-age effects on late stages of processing sad faces
}

\author{
Mara Fölster $^{1} \cdot$ Katja Werheid $^{1}$
}

Published online: 31 March 2016

(C) Psychonomic Society, Inc. 2016

\begin{abstract}
Faces convey important information on interaction partners, such as their emotional state and age. Faces of the same age are, according to recent research, preferentially processed. The aim of the present study was to investigate whether the neural processes underlying this own-age effect are influenced by the emotional expression of the face, and to explore possible explanations such as the frequency or quality of contact to own-age versus other-age groups. Event-related potentials were recorded while 19 younger (18-30 years) and 19 older (64-86 years) observers watched younger and older sad and happy faces. Sad but not happy faces elicited higher late positive potential amplitudes for own-age than for other-age faces. This own-age effect was significant for older, but not for younger, observers, and correlated with the quality of contact with the own-age versus the other-age group. This pattern suggests that sad own-age faces are motivationally more relevant.
\end{abstract}

Keywords Own-age effect · Facial expression · Event-related potentials $\cdot$ Late positive potential $\cdot$ Emotion

Faces convey crucial information for social interactions: They signal the emotional state of our interaction partners, and also provide important social information on their age, sex, and race. Recent research has revealed preferential processing of faces belonging to one's same age group (own-age faces).

Mara Fölster

mara.foelster@hu-berlin.de

1 Department of Psychology, Clinical Gerontopsychology, Humboldt-Universität zu Berlin, Rudower Chaussee 18, D-12489 Berlin, Germany
They are looked at longer (Ebner, He, \& Johnson, 2011), are more distracting (Ebner \& Johnson, 2010), and are remembered more accurately (Harrison \& Hole, 2009; Neumann, End, Luttmann, Schweinberger, \& Wiese, 2015; Wiese, Wolff, Steffens, \& Schweinberger, 2013; Wolff, Wiese, \& Schweinberger, 2012; see Rhodes \& Anastasi, 2012, and Wiese, Komes, \& Schweinberger, 2013, for reviews), and their emotional expressions may be more accurately decoded (Malatesta, Izard, Culver, \& Nicolich, 1987; but see Borod et al., 2004; Ebner et al., 2011; Ebner \& Johnson, 2009; Ebner, Johnson, \& Fischer, 2012; Ebner et al., 2013; Hühnel, Fölster, Werheid, \& Hess, 2014; Murphy, Lehrfeld, \& Isaacowitz, 2010) than faces from other age groups (other-age faces).

Neuroscientific research further suggests own-age effects in the neural processing of emotional faces. Specifically, functional magnetic resonance imaging (fMRI) studies have revealed greater activity in the amygdala (Ebner et al., 2013; Wright et al., 2008), insula, and medial prefrontal cortex (mPFC; Ebner et al., 2013) when observers watch own-age versus other-age faces, possibly reflecting a higher interest in, perceived similarity with, and self-relevance of own-age faces. An interaction was reported for the ventral part of the $\mathrm{mPFC}$, in which own-age effects were found only for neutral and happy, but not for angry, faces (Ebner et al., 2013).

Due to their excellent time resolution, event-related potentials (ERPs) are well-suited to investigate the neurofunctional processes underlying the own-age effect. Surprisingly, previous ERP studies exploring own-age effects have exclusively focused on neutral faces, despite evidence that facial emotion may modulate age effects on decoding accuracy (Ebner, He, \& Johnson, 2011; Ebner \& Johnson, 2009; Ebner, Riediger, \& Lindenberger, 2010). Regarding the neural correlates of these processes, it has been suggested that emotion effects may even override age-of-face effects (Ebner et al., 2013). 
The aim of the present study was to investigate the combined effects of facial age, observer age, and emotional expression with ERPs. Specifically, we wished to investigate whether these effects are related to earlier perceptual or later evaluative processing stages. In the following discussion, we briefly review ERP evidence regarding age and emotion effects on the early (N170) and late (late positive potential, LPP) face- and emotion-related ERP components. For a more comprehensive review of the ERP literature, also including findings on the repetition- and memory-related N250, which was considered less relevant here, we refer the reader to Wiese, Komes, et al. (2013).

The most widely studied face-sensitive ERP component is the N170 (see Eimer, 2011, for a review), an early negative deflection peaking around $170 \mathrm{~ms}$ over occipitotemporal sites that is associated with the structural processing of faces and is larger for faces than for object stimuli (e.g., Bentin, Allison, Puce, Perez, \& McCarthy, 1996). Some previous studies have revealed increased N170 amplitudes for other-race than for own-race faces (Caharel et al., 2011; Gajewski, Schlegel, \& Stoerig, 2008; Herrmann et al., 2007; Stahl, Wiese, \& Schweinberger, 2008; Walker, Silvert, Hewstone, \& Nobre, 2007; Wiese, 2012; Wiese, Kaufmann, \& Schweinberger, 2014). Since own-race and own-age effects on ERPs are partly comparable (Ebner, He, Fichtenholtz, McCarthy, \& Johnson, 2011; Wiese, Schweinberger, \& Hansen, 2008), this finding might extend to own-age effects. However, so far, own-age effects on the N170 have not been confirmed for neutral faces (Wiese, Komes, \& Schweinberger, 2012; Wiese et al., 2008), suggesting that partly different neural processes may underlie own-age and own-race effects. Instead, both younger and older observers showed higher N170 amplitudes for older than for younger faces (Wiese et al., 2012; Wiese et al., 2008), indicating that structural encoding may be more difficult for older faces, for both older and younger observers. Concerning emotion effects on the N170, the results are mixed: Whereas some studies have shown a modulation by emotion (Batty \& Taylor, 2003; Blau, Maurer, Tottenham, \& McCandliss, 2007; Krombholz, Schaefer, \& Boucsein, 2007; Luo, Feng, He, Wang, \& Luo, 2010; Rellecke, Palazova, Sommer, \& Schacht, 2011), others have not (Balconi \& Lucchiari, 2005; Eimer \& Holmes, 2002, 2007; Eimer, Holmes, \& McGlone, 2003; Holmes, Vuilleumier, \& Eimer, 2003; Schupp et al., 2004). Thus, the question of whether emotional expressions moderate the N170 has not yet been clarified. Rellecke, Sommer, and Schacht (2012) suggested that "low-level" differences between facial expressions may account for the emotion effects reported in some studies.

The LPP is an enhanced positivity after $300 \mathrm{~ms}$ over parietal sites that reflects elaborate processing (Schacht \& Sommer, 2009) and is more commonly used to study the processing of emotional faces. The LPP amplitude is enhanced for emotional stimuli with high intrinsic relevance (Schupp et al., 2004), and for facial expressions with negative as compared with positive valence (Schupp et al., 2004) and with higher as compared with lower emotional intensity (Duval, Moser, Huppert, \& Simons, 2013; Recio, Schacht, \& Sommer, 2014). The LPP is assumed to reflect sustained elaborate and affective processing, initiated by a high intrinsic relevance of the emotional stimuli (Cuthbert, Schupp, Bradley, Birbaumer, \& Lang, 2000; Kayser et al., 1997; Schacht \& Sommer, 2009; Schupp et al., 2000). There is evidence for own-race effects on LPP amplitudes (He, Johnson, Dovidio, $\&$ McCarthy, 2009), at least when the race of the face was task-relevant (Stahl, Wiese, \& Schweinberger, 2010). Again, this finding might extend to own-age effects. To our knowledge, this was the first study to investigate own-age effects on LPPs. Several previous studies have examined the impact of age correspondence on the old-new recognition effect measured at similar time intervals $(300-800 \mathrm{~ms})$ at centroparietal electrode sites, considered to reflect recollection-based recognition. This old-new effect was enhanced for own-age as compared with other-age faces (Wiese et al., 2012; Wiese et al., 2008; but see Wolff et al., 2012). Focusing on amplitude differences, rather than the amplitude itself, these results allow for no direct conclusions concerning own-age effects on LPPs. Furthermore, previous research has not examined whether own-age effects on LPP amplitudes are modulated by the emotional expression of the face. The aim of the present study was to extend these results by analyzing the combined effects of age congruence and emotion on LPP amplitudes.

A further aim of the present study was to explore the possible mechanisms underlying own-age effects. Own-age effects on recognition memory have been explained by higher expertise due to a higher quantity of contact with same-aged individuals (Harrison \& Hole, 2009; Rhodes \& Anastasi, 2012; Wiese et al., 2012; Wiese, Wolff, et al., 2013; Wolff et al., 2012). As an alternative or additional explanation, the own-age effect may be related to the quality of contact, to motivational processes, and to higher identification with the own-age group (Hugenberg, Young, Bernstein, \& Sacco, 2010; Young \& Hugenberg, 2010). Thus, our aim was to explore whether own-age effects on ERPs were associated with the quantity and/or quality of contact and identification with the own-age group.

To sum up, the major aims of the present study were to examine whether own-age effects (1) are moderated by the emotional expression of the face, (2) emerge during earlier perceptual or later evaluative processing stages, and (3) are associated with in-group identification and with quantity or quality of contact. To explore these questions, we recorded an electroencephalogram (EEG) while younger and older observers watched pictures of younger and older faces showing sad and happy expressions, and analyzed age and emotion effects on one early (N170) and one later (LPP) ERP. 


\section{Method}

\section{Participants}

One younger male and one older female observer were excluded from the analyses due to an excessive number of artifacts in the EEG. The remaining sample included 19 older (64-85 years old, $M=70.47, S D=6.15$; ten men, nine women) and 19 younger (18-30 years old, $M=24.84, S D=3.85$; nine men, ten women) observers. All had normal or corrected-to-normal vision and reported being free of neurological or psychiatric diseases. They were recruited via an online participant database at the Humboldt-Universität $\mathrm{zu}$ Berlin and by flyers distributed during a lecture at the Third Age University at Humboldt-Universität zu Berlin. They received $€ 24$ for participating. The study was approved by the ethics committee of Humboldt-Universität zu Berlin.

The younger observers had more years of education (younger observers: $M=12.50, S D=0.89$; older observers: $M=$ $10.75, S D=1.65), t(30)=3.72, p=.001$, and showed-as expected - higher levels of fluid intelligence, as assessed by the reasoning subtest (Subtest 3) of the LPS (Leistungsprüf system; Horn, 1983), in which nonmatching figures have to be identified among lines of logically related figures (younger observers: $M=29.42, S D=5.49$, older observers: $M=$ $21.89, S D=4.43), t(36)=4.65, p<.001$. However, the older observers were higher in crystallized intelligence, as assessed by the WST (Wortschatztest; Schmidt \& Metzler, 1992), a German vocabulary test in which a target word has to be identified among five pseudowords (younger observers: $M=31.42, S D=3.25$, older observers: $M=35.16$,
$S D=2.81), t(36)=3.79, p=.001$. Relevant cognitive deficits could be excluded because none of the participants were below one standard deviation of the norm in these cognitive tests.

\section{Stimulus material}

Pictures of 56 younger (28 men, 28 women, age range: 19-31 years, $M=24.04, S D=3.38$ ) and 56 older ( 28 men, 28 women, age range: $69-80$ years, $M=73.16, S D=2.85$ ) models showing sad and happy facial expressions were selected from the FACES database (Ebner et al., 2010). The intensity of the facial expressions was systematically varied, because previous research had shown own-age effects on emotion expression decoding accuracy for ambiguous (Malatesta et al., 1987) but not for intense (e.g., Ebner \& Johnson, 2009; Ebner et al., 2012) expressions. Pictures of varying intensities $(10 \%$, $50 \%$, and $90 \%$ ) were created by morphing the chosen pictures to a neutral picture from the same model using Abrosoft FantaMorph 4. Two sets were created to control for idiosyncratic effects of the face models, each consisting of 56 models (28 older, 28 younger) displaying sad facial expressions and 56 different models displaying happy facial expressions, in $10 \%, 50 \%$, and $90 \%$ intensities, respectively. To minimize eye movements, the original face pictures were cut to standardized image sections, with the external crops located close to the face. These images were presented on a computer monitor $(33.5 \times 27.2 \mathrm{~cm})$ using the Presentation software. The viewing angle was $10^{\circ} \times 7.5^{\circ}$, and the screen resolution was 96.42 pixels per inch. Figure 1 shows examples of two images.

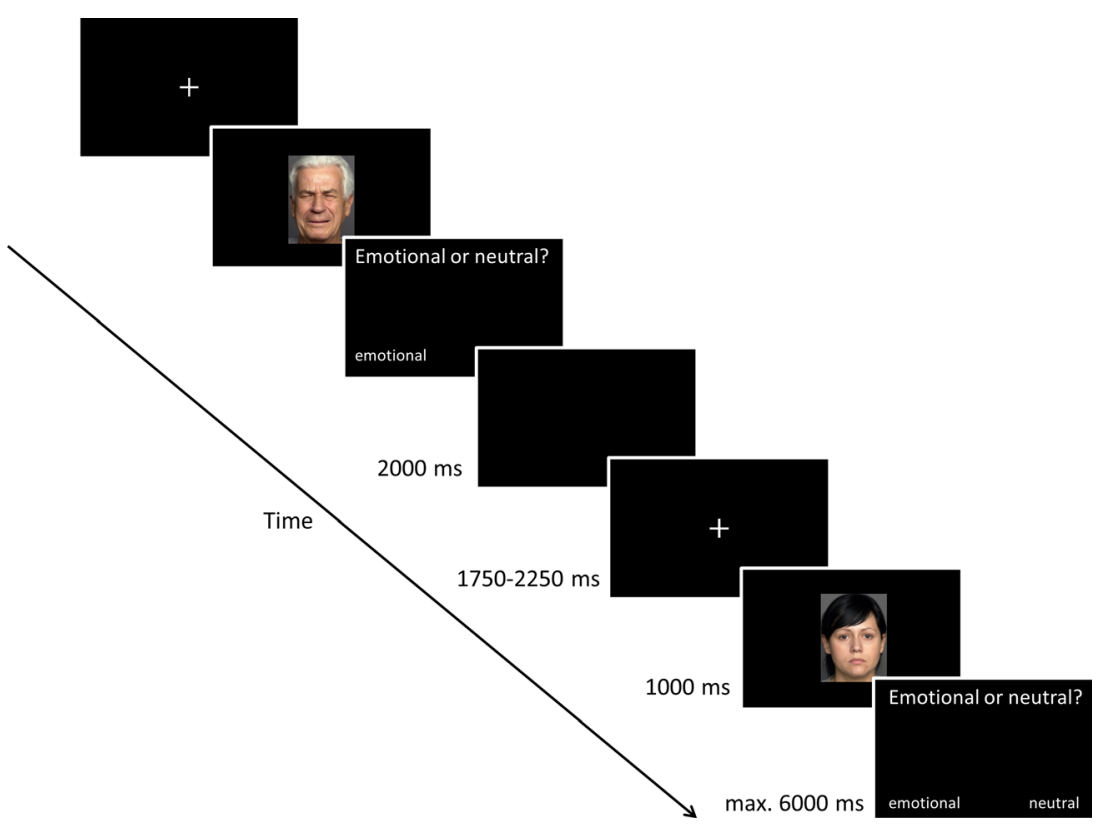

Fig. 1 Trial event timing and stimulus examples 


\section{Experimental design}

The EEG experiment was divided in two blocks, one for each emotion. The block design was chosen to avoid an influence of unequal perceived frequencies of each emotional valence on the LPP amplitudes (Cacioppo, Crites, Gardner, \& Berntson, 1994; Donchin \& Coles, 1988). Since previous research had pointed to age effects on the perceived valence of neutral expressions (Czerwon, Lüttke, \& Werheid, 2011), we wanted to circumvent any interference of these effects with the age effects on LPPs. The order of blocks was counterbalanced across observers. At the beginning of the first block, three training trials were conducted with stimuli that were not used in the experiment. Each trial started with a fixation cross $(1,750-2,250$ $\mathrm{ms})$, followed by a stimulus $(1,000 \mathrm{~ms})$. After the stimulus had disappeared, observers were asked to spontaneously and quickly classify the face as emotional or neutral by pressing one of two keys. The assignments of keys to the response options were counterbalanced across observers. If observers did not respond within $2,000 \mathrm{~ms}$, an instruction asking them to react faster appeared on the screen; if no response was shown within the next $4,000 \mathrm{~ms}$, the next trial started. The intertrial interval was $2,000 \mathrm{~ms}$. In each block, observers were allowed to rest after each quarter of the stimuli had been presented. Figure 1 presents the trial event timing.

\section{Procedure}

Prior to the EEG experiment, observers worked on the WST and the reasoning subtest of the LPS, as described above. The EEG experiment was conducted in a light- and soundattenuated room. After the EEG experiment, observers decoded the emotional facial expressions by rating the stimuli according to the intensity of their displayed sadness and happiness on 5-point scales, anchored with 0 (not at all) and 4 (very intense). Ratings were considered correct if the rating on the target emotion was higher than the rating on the nontarget emotion. Sad faces $(10 \%, 50 \%, 90 \%)$ were rated correctly by $37 \%, 77 \%$, and $94 \%$ of the observers, and happy faces $(10 \%$, $50 \%, 90 \%$ ) by $20 \%, 88 \%$, and $99 \%$ of the observers. After that, the observers worked on two graphical items measuring the perceived overlap of the self and the groups of younger and older adults (via the Inclusion of Other in the Self Scale [IOS] by Aron, Aron, \& Smollan, 1992; adapted by Schubert $\&$ Otten, 2002), and were asked to indicate how often they had contact in person with older and with younger adults, respectively, on 8-point scales $(1=$ very seldom, $2=$ once per year, 3 $=2-3$ times per year, $4=$ once per month, $5=2-3$ times per month, $6=$ once per week, $7=2-3$ times per week, $8=$ every day). Furthermore, observers described their quality of contact with older and younger adults, respectively, on the following 7-point bipolar continua, with higher scores representing higher quality of contact: unpleasant-pleasant, destructiveconstructive, involuntary-voluntary, aloof-intimate, unequalequal status, superficial-intensive, and impersonal-personal (Tzeng \& Jackson, 1994). Mean scores were calculated for each target age group. The reliability of the latter questionnaire was good for the younger observers (younger targets: Cronbach's $\alpha=.86$; older targets: Cronbach's $\alpha=.84$ ), and acceptable for the older ones (younger targets: Cronbach's $\alpha=$ .89; older targets: Cronbach's $\alpha=.72$ ). The duration of the experiment was approximately $1.5 \mathrm{~h}$.

\section{Electrophysiological recording}

A 64-channel EEG was recorded using a Brain Amp EEG amplifier and the Brain Recorder software (Brain Products, Munich, Germany). Active $\mathrm{Ag}-\mathrm{AgCl}$ electrodes were mounted in an electrode cap (ActiCap System). An electrooculogram (EOG) was recorded from FP2 and IO below the right eye, to control for eye artifacts. The TP9 electrode served as the initial common reference, and $\mathrm{AFz}$ as the ground. Impedances were kept below $5 \mathrm{k} \Omega$. A sampling rate of $250 \mathrm{~Hz}$ and an online bandpass filter at 0.01 to $70 \mathrm{~Hz}$ were applied during recording. The time constant was set at $10 \mathrm{~s}$.

\section{Data analysis}

The EEG data were corrected for eye movements and blink artifacts using the multiple-source eye correction method (surrogate method; Berg \& Scherg, 1994), implemented in BESA 5.2 (Brain Electrical Source Analysis; MEGIS Software GmbH, Gräfelfing, Germany) and re-referenced offline to the average reference. A low-pass filter of $30 \mathrm{~Hz}$ was used. The continuous EEG data were segmented from 200 to $1,000 \mathrm{~ms}$ relative to stimulus onset, with the first $200 \mathrm{~ms}$ as the baseline. Artifacts were rejected semiautomatically using a gradient criterion of $50 \mu \mathrm{V}$, a difference criterion of $200 \mu \mathrm{V}$, and an amplitude criterion of $100 \mu \mathrm{V}$. The minimum number of trials per condition was 16 , and the mean number of trials per condition was 25.9. The remaining trials were averaged for each experimental condition and recalculated to the average reference. The EOG channels were excluded. Average ERP waveforms were calculated for each experimental condition and filtered with a $10-\mathrm{Hz}$ high cutoff for visual presentation. For the N170, peak analyses were carried out between 140 and $210 \mathrm{~ms}$ after stimulus onset. After visual inspection, the LPP amplitude was defined as the mean voltage in the interval of 300-600 ms after stimulus onset. Pooled waveforms were calculated separately for the N170 and LPP at the electrodes where the component showed its maximum, as well as at their respective contralateral 
homologues (N170: P7, P8, PO7, PO8, TP7, TP8, TP9, TP10; $L P P: \mathrm{Pz}, \mathrm{P} 1, \mathrm{P} 2, \mathrm{POz}, \mathrm{PO} 3, \mathrm{PO} 4){ }^{1}$

\section{Results}

\section{N170}

The results of the 2 (Observer Age $) \times 2($ Face Age $) \times 2$ (Emotion) $\times 3$ (Intensity) analysis of variance (ANOVA) on N170 amplitudes are displayed in Table 1. Concordant with previous results, main effects of observer age as well as face age indicated larger N170 amplitudes for older $(M=-8.60$, $S D=3.03)$ than for younger $(M=-4.23, S D=2.04)$ observers, as well as for older $(M=-6.65, S D=3.43)$ than for younger $(M=-6.17, S D=3.34)$ faces. Neither the Observer Age $\times$ Face Age interaction nor the Observer Age $\times$ Face Age $\times$ Emotion interaction reached significance. Thus, we found no own-age effects on N170 amplitudes.

\section{LPP}

The results of the 2 (Observer Age $) \times 2($ Face Age $) \times 2$ (Emotion) $\times 3$ (Intensity) ANOVA on LPP amplitudes are also displayed in Table 1. A main effect of observer age indicated larger LPP amplitudes for younger $(M=5.93, S D=4.18)$ than for older $(M=3.58, S D=1.94)$ observers. Furthermore, the Observer Age $\times$ Face Age $\times$ Emotion interaction was significant. Follow-up analyses revealed no significant Observer Age $\times$ Face Age interaction for happiness, $F(1,36)=$ $1.32, p=.259, \eta_{\mathrm{p}}{ }^{2}=.035$, but this interaction did emerge for sadness, $F(1,36)=5.02, p=.031, \eta_{\mathrm{p}}^{2}=.122$. LPP amplitudes were higher for sad faces in the own-age group, as compared with the other-age group. However, this difference was only significant for older observers (younger faces: $M=3.27, S D=2.04$; older faces: $M=3.61, S D=$ 1.99), $t(18)=2.92, p=.009$, but not for younger observers (younger faces: $M=6.03, S D=4.30$; older faces: $M=$ 5.87, $S D=4.37), t(18)=0.85, p=.407$. Grand-mean ERPs for sad faces as a function of observer age and face age are depicted in Fig. 2.

In addition, the Face Age $\times$ Intensity interaction was significant. Follow-up $t$ tests revealed that LPP amplitudes were higher for older $(M=4.96, S D=3.54)$ than for younger $(M=$ $4.57, S D=3.42$ ) faces at $90 \%$ intensity, $t(37)=2.88, p=.007$,

\footnotetext{
${ }^{1}$ Previous research has often revealed a lateralization effect for the N170, which may be weaker in older adults (e.g., Gao et al., 2009). However, inclusion of the Hemisphere factor yielded neither a significant main effect on N170 amplitudes nor significant interactions with any of the other factors (all $p \mathrm{~s}>.05$ ). Thus, for clarity's sake, N170 amplitudes were pooled across hemispheres, and the results are reported without inclusion of the Hemisphere factor.
}

Table 1 Results of ANOVAs on N170 and LPP amplitudes, as a function of observer age, face age, emotion, and intensity, as well as their interactions

\begin{tabular}{|c|c|c|c|c|c|c|c|c|}
\hline \multirow[t]{2}{*}{ Factor } & \multicolumn{4}{|l|}{$\mathrm{N} 170$} & \multicolumn{4}{|l|}{ LPP } \\
\hline & $d f$ & $F$ & $p$ & $\eta_{\mathrm{p}}^{2}$ & $d f$ & $F$ & $p$ & $\eta_{\mathrm{p}}^{2}$ \\
\hline OA (Observer age) & 1,36 & 27.10 & $<.001$ & .429 & 1,36 & 4.93 & .033 & .120 \\
\hline FA (Face age) & 1,36 & 29.93 & $<.001$ & .454 & 1,36 & 3.90 & .056 & .098 \\
\hline E (Emotion) & 1,36 & 0.51 & .481 & .014 & 1,36 & 0.43 & .518 & .012 \\
\hline I (Intensity) & 2,72 & 0.21 & .808 & .006 & 2,59 & 0.05 & .930 & .001 \\
\hline $\mathrm{OA} \times \mathrm{FA}$ & 1,36 & 1.94 & .172 & .051 & 1,36 & 0.56 & .459 & .015 \\
\hline $\mathrm{OA} \times \mathrm{E}$ & 1,36 & 2.02 & .164 & .053 & 1,36 & 0.87 & .356 & .024 \\
\hline $\mathrm{OA} \times \mathrm{I}$ & 2,72 & 0.37 & .693 & .010 & 2,59 & 2.87 & .074 & .074 \\
\hline $\mathrm{FA} \times \mathrm{E}$ & 1,36 & 0.89 & .351 & .024 & 1,36 & 0.82 & .371 & .022 \\
\hline $\mathrm{FA} \times \mathrm{I}$ & 2,72 & 1.36 & .262 & .037 & 2,72 & 4.39 & .016 & .109 \\
\hline $\mathrm{E} \times \mathrm{I}$ & 2,72 & 0.32 & .724 & .009 & 2,72 & 4.97 & .009 & .121 \\
\hline $\mathrm{OA} \times \mathrm{FA} \times \mathrm{E}$ & 1,36 & 0.21 & .646 & .006 & 1,36 & 5.87 & .021 & .140 \\
\hline $\mathrm{OA} \times \mathrm{FA} \times \mathrm{I}$ & 2,72 & 1.36 & .262 & .036 & 2,72 & 2.47 & .092 & .064 \\
\hline $\mathrm{OA} \times \mathrm{E} \times \mathrm{I}$ & 2,72 & 2.44 & .094 & .063 & 2,72 & 2.27 & .111 & .059 \\
\hline $\mathrm{FA} \times \mathrm{E} \times \mathrm{I}$ & 2,72 & 0.14 & .867 & .004 & 2,60 & 0.34 & .673 & .009 \\
\hline $\mathrm{OA} \times \mathrm{FA} \times \mathrm{E} \times \mathrm{I}$ & 2,72 & 0.17 & .844 & .005 & 2,60 & 1.23 & .295 & .033 \\
\hline
\end{tabular}

but did not differ at the $50 \%, t(37)=1.97, p=.057$, and $10 \%$, $t(37)=1.04, p=.306$, intensities.

Apart from that, the Emotion $\times$ Intensity interaction reached significance. For happiness, follow-up $t$ tests revealed higher LPP amplitudes at 10\% $(M=4.97, S D=3.60)$ than at $90 \%(M=4.68, S D=3.35)$ intensity, $t(37)=2.39, p=.022$. For sadness, contrariwise, amplitudes were lower at $10 \%(M=$ $4.51, S D=3.48)$ than at $90 \%(M=4.85, S D=3.65)$ intensity, $t(37)=2.32, p=.026$. LPP amplitudes did not differ between the $50 \%$ and $10 \%$ or the $50 \%$ and $90 \%$ intensities, for either happiness or sadness (all $p \mathrm{~s}>.05)^{2}$

\section{Facial expression decoding}

Participants' facial expression decoding accuracy was analyzed in a $2($ Observer Age $) \times 2($ Face Age $) \times 3$ (Intensity $) \times$ 2 (Emotion) ANOVA on the proportions of accurate answers in the rating task after the EEG experiment (see Table 2). There was no general or emotion-specific own-age effect on facial expression decoding, as indicated by nonsignificant Observer Age $\times$ Face Age and Observer Age $\times$ Face Age $\times$ Emotion interactions. However, we did observe a significant Observer Age $\times$ Face Age $\times$ Emotion $\times$ Intensity interaction . Separate 2 (Observer Age) $\times 2$ (Face Age $) \times 3$ (Intensity)

\footnotetext{
${ }^{2}$ Previous research has suggested own-gender effects on ERPs (Wolff, Kemter, Schweinberger, \& Wiese, 2014) and influences of facial age on gender perceptions (Kloth, Damm, Schweinberger, \& Wiese, 2015). However, we did not find significant emotion-specific or general owngender effects on either N170 or LPP amplitudes (all $p$ s $>.05$ ).
} 


\section{N170}

\section{Sadness}

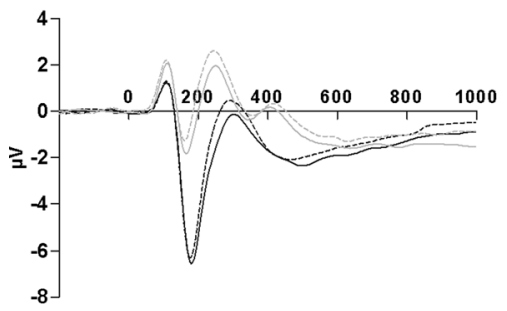

\section{Happiness}

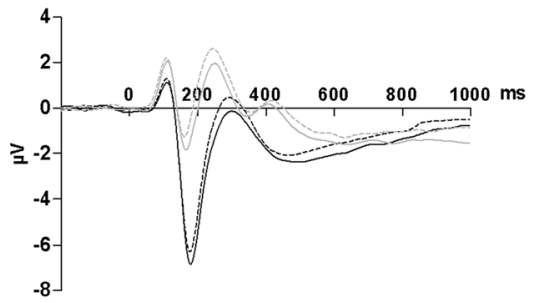

\section{Late Positive Potential}

\section{Sadness}

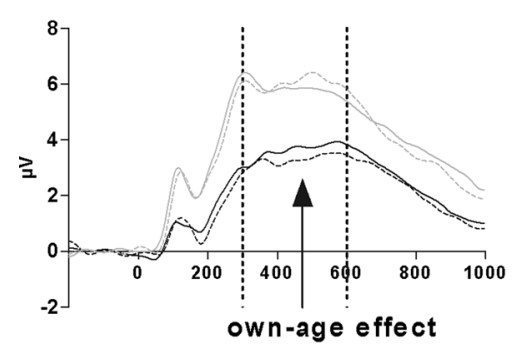

Happiness

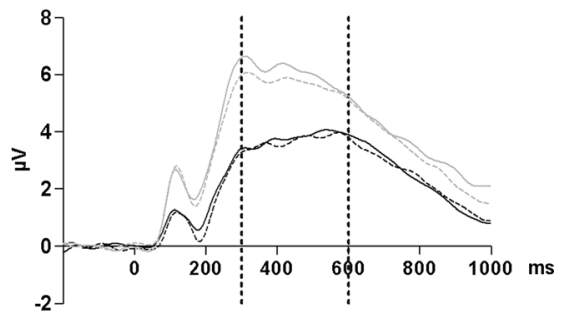

\footnotetext{
- Old observer, old face

----. Old observer, young face

Young observer, old face

Young observer, young face
}

Fig. 2 Grand-mean N170 and LPP amplitudes for pooled electrodes, shown separately for sadness and happiness, as a function of observer age and face age

Table 2 Results of ANOVAS on hit rates, as a function of observer age, face age, intensity, emotion, and their interactions

\begin{tabular}{llrll}
\hline Factor & \multicolumn{1}{l}{ df } & \multicolumn{1}{l}{$p$} & $\eta_{\mathrm{p}}{ }^{2}$ \\
\hline OA (Observer age) & 1,36 & 2.86 & .100 & .074 \\
FA (Face age) & 1,36 & 8.75 & .005 & .196 \\
E (Emotion) & 1,36 & 0.03 & .868 & .001 \\
I (Intensity) & 2,58 & 777.06 & $<.001$ & .956 \\
OA $\times$ FA & 1,36 & 0.18 & .675 & .005 \\
OA $\times$ I & 2,58 & 0.86 & .427 & .023 \\
OA $\times$ E & 1,36 & 1.45 & .237 & .039 \\
FA $\times$ E & 1,36 & 1.75 & .195 & .046 \\
FA $\times$ I & 2,55 & 54.57 & $<.001$ & .603 \\
E $\times$ I & 2,63 & 44.03 & $<.001$ & .550 \\
OA $\times$ FA $\times$ E & 1,36 & 1.75 & .195 & .046 \\
OA $\times$ FA $\times$ I & 2,55 & 0.57 & .525 & .016 \\
FA $\times$ E $\times$ I & 2,62 & 28.89 & $<.001$ & .445 \\
OA $\times$ E $\times$ I & 2,63 & 1.46 & .239 & .039 \\
OA $\times$ FA $\times$ E $\times$ I & 2,62 & 10.96 & $<.001$ & .233 \\
\hline
\end{tabular}

ANOVAs for happiness and sadness revealed no significant Observer Age $\times$ Face Age $\times$ Intensity interaction for happiness, $F(1,54)=2.79, p=.085, \eta_{\mathrm{p}}{ }^{2}=.072$, but this interaction did emerge for sadness, $F(2,62)=7.38, p=.002, \eta_{\mathrm{p}}{ }^{2}=.170$. Separate 2 (Face Age) $\times 3$ (Intensity) ANOVAs for younger and older observers for sadness revealed significant interactions for both younger, $F(2,30)=21.87, p<.001, \eta_{\mathrm{p}}{ }^{2}=.549$, and older, $F(2,32)=73.05, p<.001, \eta_{\mathrm{p}}{ }^{2}=.802$, observers. Both younger, $t(18)=5.55, p<.001$, and older, $t(18)=5.50$, $p<.001$, observers decoded 50\%-intense sad expressions more accurately in younger (younger observers: $M=.91$, $S D=.08$; older observers: $M=.79, S D=.15)$ than in older (younger observers: $M=.74, S D=.15$; older observers: $M=$ $.62, S D=.19)$ faces. For younger observers, we found no differences between the face age groups for sad expressions of $10 \%, t(18)=1.14, p=.269$, or $90 \%, t(18)=1.54, p=$ .142 , intensity. Older observers decoded 10\%-intense sad expressions more accurately in older $(M=.43, S D=.23)$ than in younger $(M=.27, S D=.18)$ faces, $t(18)=4.12, p=$ .001 , but they decoded $90 \%$-intense expressions more accurately in younger $(M=.95, S D=.07)$ than in older $(M=.89$, $S D=.12$ ) faces, $t(18)=2.87, p=.010$. Thus, older 
observers showed an own-age advantage for sad expressions of low intensity. To examine the relationship of this own-age effect to the own-age effect on LPP amplitudes, we first calculated own-age effect measures for decoding accuracy as well as for LPP amplitudes for sadness-by, for example, subtracting the decoding accuracy of sadness for the other-age group from the decoding accuracy for the own-age group - and examined the correlations between these measures. The correlation of this own-age advantage in older observers with the own-age effect in LPPs for sad faces was in the expected positive direction, but not significant, $r(18)=.111, p=.226$.

A set of 2 (Observer Age) $\times 2$ (Target Age) ANOVAs on mean scores from the IOS and from the questionnaires on the quality and quantity of contact with older and younger targets revealed significant main effects of target age for the IOS, $F(1$, $36)=11.29, p=.002, \eta_{\mathrm{p}}{ }^{2}=.239$, and quality of contact, ${ }^{3} F(1$, 34) $=4.33, p=.045, \eta_{\mathrm{p}}{ }^{2}=.113$, but not for the quantity of contact, $F(1,36)=3.98, p=.054, \eta_{\mathrm{p}}{ }^{2}=.100$. The main effects were qualified by significant Observer Age $\times$ Target Age interactions [IOS: $F(1,36)=19.21, p<.001, \eta_{\mathrm{p}}{ }^{2}=.348$; quality of contact: $F(1,34)=10.12, p=.003, \eta_{\mathrm{p}}{ }^{2}=.229$; quantity of contact: $\left.F(1,36)=45.05, p<.001, \eta_{\mathrm{p}}{ }^{2}=.556\right]$. The results of follow-up $t$ tests are displayed in Table 3. Observers identified more with the own-age group and reported higher quality of contact with the own-age than with the other-age group, but this difference was only significant for younger observers. Furthermore, both younger and older observers reported higher quantity of contact with the own-age than with the other-age group. No significant main effects of observer age were apparent $\left[\operatorname{IOS}: F(1,36)=1.80, p=.189, \eta_{\mathrm{p}}{ }^{2}=.048\right.$; quality of contact: $F(1,34)=0.11, p=.744, \eta_{\mathrm{p}}^{2}=.003$; quantity of contact: $\left.F(1,36)=0.31, p=.583, \eta_{\mathrm{p}}{ }^{2}=.008\right]$.

To examine the correlation with the LPP own-age effect, we first calculated own-age effect measures for quality and quantity of contact, for IOS scores, and for LPP amplitudes for sadness, by, for example, subtracting the quantity of contact with the other-age group from the quantity of contact with the own-age group. We observed a significant positive correlation between the LPP own-age effects for sadness and quality of contact, $r(34)=.287, p=.045$ (one-tailed tests). The correlations of the LPP own-age effect with those related to the IOS, $r(36)=.183, p=.135$, and quantity of contact, $r(36)=.041, p=.400$, however, were not significant.

\section{Discussion}

The present study was to our knowledge the first experiment investigating the combined effects of observers' and facial age and facial emotion on ERPs. As the main result of our study,

\footnotetext{
${ }^{3}$ Data were missing for two older observers because they did not fill in the last page of the quality-of-contact questionnaire.
}

Table 3 Means from questionnaires on the quality and quantity of contact and on identification with the two age groups, for younger and older observers

\begin{tabular}{|c|c|c|c|c|c|c|c|}
\hline & \multicolumn{2}{|c|}{ Younger Target } & \multicolumn{2}{|c|}{ Older Target } & \multirow[t]{2}{*}{$d f$} & \multirow[t]{2}{*}{$t$} & \multirow[t]{2}{*}{$p$} \\
\hline & $M$ & $S D$ & $M$ & $S D$ & & & \\
\hline \multicolumn{8}{|l|}{ Quality of contact } \\
\hline Younger observers & 5.50 & 0.74 & 4.74 & 0.86 & 17 & 3.06 & .007 \\
\hline Older observers & 5.11 & 0.98 & 5.27 & 0.70 & 17 & 1.08 & .294 \\
\hline \multicolumn{8}{|l|}{ Quantity of contact } \\
\hline Younger observers & 7.79 & 0.42 & 5.26 & 1.66 & 18 & 6.43 & $<.001$ \\
\hline Older observers & 6 & 1.45 & 7.37 & 1.12 & 18 & 3.2 & .005 \\
\hline \multicolumn{8}{|l|}{ IOS } \\
\hline Younger observers & 5.53 & 1.43 & 2.74 & 1.37 & 18 & 5.18 & $<.001$ \\
\hline Older observers & 4.42 & 1.46 & 4.80 & 1.90 & 18 & 0.77 & .452 \\
\hline
\end{tabular}

IOS = Inclusion of Other in the Self Scale (Aron, Aron, \& Smollan, 1992; adapted by Schubert \& Otten, 2002)

we found an own-age effect on the LPP for sadness, but not for happiness. This own-age effect emerged for older, but not for younger, observers and related to the quality of contact with the own-age group.

Our finding of an own-age effect in older observers is in line with previous reports in older observers of more pronounced own-age effects on amygdala activity when watching neutral (Wright et al., 2008) or emotional (Ebner et al., 2013) faces. On the basis of these findings, Ebner et al. (2013) suggested that age may be a more salient and relevant feature for older adults, who may be more frequently reminded of their age because of age-related declines in various domains of functioning. However, so far, this explanation is only speculative and needs empirical investigation.

Our finding that the own-age effect on the neural processing of faces was moderated by emotional expression confirms and extends recent findings obtained with fMRI (Ebner et al., 2013). Exploiting the higher temporal resolution of the ERP method, we could show that these own-age effects coincide with alterations of the LPP, reflecting late evaluative stages of information processing (Herbert, Kissler, Junghöfer, Peyk, \& Rockstroh, 2006; Schacht \& Sommer, 2009). Similar LPP effects have been reported for own-race effects in response to neutral faces (He et al., 2009). In contrast, we found no ownage effects on earlier (N170) perceptual processing stages, confirming and extending previous studies on own-age effects in response to neutral faces (see Wiese, Komes, et al., 2013, for a review). Our findings suggest that age congruence influences later stages in the processing of emotional faces, which are commonly associated with the faces' motivational relevance (Cuthbert et al., 2000; Schacht \& Sommer, 2009; Schupp et al., 2007), rather than with their structural encoding. As previous research reported own-race effects on N170 amplitudes (e.g., Caharel et al., 2011; Wiese et al., 2014), our results 
support the view that the neural processes underlying ownage and own-race effects partly differ (Wiese, Komes, et al., 2013).

The own-age effect for sad faces in older observers suggests preferential processing of sad faces in old-age peers. Motivational sources as well as behavioral consequences of such a preference are conceivable. Their direction, however, is unclear, since this preference might facilitate both social support and avoidance of social interactions with sad peers. The ERP measures obtained in our study leave this point open for future studies that could combine physiological parameters with behavioral and motivational measures suited to measure appetence or valence.

Concerning the possible mechanisms underlying ownage effects, observers identified themselves more with the own-age group and reported a higher quality and quantity of contact with the own-age group. Furthermore, the significant positive correlation between the own-age effects on LPP amplitudes and on quality of contact indicates that individuals with close contact to age peers show ERP evidence of enhanced motivational relevance of sad faces from the same age group. However, the quantity of contact and identification with the own-age-group were not related to the own-age effect on LPPs. This is in contrast to previous reports of the quantity of contact being related to effects of facial age on ERPs and recognition memory (Wolff et al., 2012). In the present study, the quantity of contact was assessed with a one-item questionnaire. Future research should examine whether significant correlations with LPP amplitudes would emerge for more reliable measures. As an alternative explanation, Wolff et al. (2012) did not examine emotional stimuli, but ERP old-new effects, which may be more sensitive to repeated prior exposure, and thus to quantitative aspects of contact with age peers.

Our finding that the own-age effect was specific for sadness opens up several considerations regarding the particular significance of this emotion, as distinct from happiness. Since the LPP has been associated with the intrinsic relevance of stimuli (Schupp et al., 2004), our result may reflect a higher relevance of sad faces when they are from own-aged rather than otheraged individuals. Happiness may differ from sadness in this respect because a smile may strongly signal affiliation, and thereby overrule group boundaries (van der Schalk et al., 2011), rendering happy faces of own-aged and other-aged individuals equally relevant. This is in line with previous reports of attenuated in-group effects for happy faces. Some studies examining facial mimicry - that is, the imitation of emotional expressions - have shown in-group effects for negative, but not for positive, emotions (Bourgeois \& Hess, 2008; van der Schalk et al., 2011), and the own-race effect in emotion decoding accuracy was smallest for happiness (see Elfenbein \& Ambady, 2002, for a review). Also in line with this assumption, in a recent study of our own group, we found an emotion-specific own-age advantage in decoding accuracy for sadness, but not for happiness (Fölster, Hess, Hühnel, \& Werheid, 2015). A possible limitation of the present study is its focus on one positive and one negative emotional category, due to methodological particularities of the ERP method such as the high sensitivity of the LPP to imbalanced frequencies of stimulus categories. Sadness was chosen on the basis of our previous research (Fölster et al., 2015). Opposing other negative emotions to happy faces with respect to the own-ageeffect on ERPs will be a valuable topic for future research. Furthermore, future research may examine whether our results may expand to spontaneous or dynamic facial expressions, and to middle-aged adults.

Another interesting question for further research will be whether the own-age effect extends to implicit behavioral measures such as facial mimicry, or explicit measures such as decoding accuracy. A recent study of our group showed no own-age effect on facial mimicry (Hühnel et al., 2014), but results have been mixed for decoding accuracy. As a possible explanation, an own-age effect on decoding accuracy was only found when expressions were difficult to decode. Thus, previous studies with comparatively low decoding accuracy have shown an own-age effect (Fölster et al., 2015; Malatesta et al., 1987), whereas those with higher decoding accuracy did not (Borod et al., 2004; Ebner, He, \& Johnson, 2011; Ebner \& Johnson, 2009; Ebner et al., 2012; Ebner et al., 2013; Hühnel et al., 2014). Also in line with this assumption, in the present study, we only found an own-age effect on decoding accuracy for sad expressions of low intensity, and only for older observers. As a possible explanation of this pattern, observers may need more cognitive resources to decode difficult emotional stimuli, possibly leading to a higher influence of motivational factors. It is conceivable that the own-age effect might in this way affect decoding accuracy in everyday interactions, in which ambiguous or mixed expressions often occur. However, more research investigating own-age effects on decoding accuracy for expressions of varying intensities will be needed to elucidate this point.

The present study was the first analyzing the combined effects of facial age and emotion on ERPs. Future replications of the study including a middle-aged sample and larger sample sizes are recommended. To overcome a further limiting aspect, the relevance of the frequency of contact should be assessed more precisely in future studies, in order to reliably examine a possible relationship to own-age effects on LPPs.

In summary, we found an own-age effect on ERPs for sad, but not for happy, faces, which may be due either to a higher perceived relevance of sadness shown by own-aged individuals, or to the strong impact of smiling, signaling affiliation across age group boundaries. This own-age effect for sadness 
was found in later, evaluative (Herbert et al., 2006; Schacht \& Sommer, 2009), but not in earlier, perceptual processing stages, and was related to the quality, but not the quantity, of contact or identification with the own-age group. This pattern of results supports the view that higher motivational relevance (Cuthbert et al., 2000; Kayser et al., 1997; Schacht \& Sommer, 2009; Schupp et al., 2000) may underlie preferential processing of sad facial expressions in own-age peers.

Author note This research was funded by Grant Number WE 4836/1-1 from the German Research Foundation. We thank Katherine Jung for assistance in data collection and Rainer Kniesche for assistance with programming.

\section{References}

Aron, A., Aron, E. N., \& Smollan, D. (1992). Inclusion of other in the self scale and the structure of interpersonal closeness. Journal of Personality and Social Psychology, 63, 596-612. doi:10.1037/ 0022-3514.63.4.596

Balconi, M., \& Lucchiari, C. (2005). Event-related potentials related to normal and morphed emotional faces. Journal of Psychology, 139, 176-192. doi:10.3200/JRLP.139.2.176-192

Batty, M., \& Taylor, M. J. (2003). Early processing of the six basic facial emotional expressions. Cognitive Brain Research, 17, 613-620. doi:10.1016/S0926-6410(03)00174-5

Bentin, S., Allison, T., Puce, A., Perez, E., \& McCarthy, G. (1996). Electrophysiological studies of face perception in humans. Journal of Cognitive Neuroscience, 8, 551-565. doi:10.1162/jocn.1996.8.6.551

Berg, P., \& Scherg, M. (1994). A multiple source approach to the correction of eye artifacts. Electroencephalography and Clinical Neurophysiology, 90, 229-241. doi:10.1016/0013-4694(94)90094-9

Blau, V. C., Maurer, U., Tottenham, N., \& McCandliss, B. D. (2007). The face-specific N170 component is modulated by emotional facial expression. Behavioral and Brain Functions, 3, 1-13. doi:10.1186/1744-9081-3-7

Borod, J., Yecker, S., Brickman, A., Moreno, C., Sliwinski, M., Foldi, N., . . . Welkowitz, J. (2004). Changes in posed facial expression of emotion across the adult life span. Experimental Aging Research, 30, 305-331. doi:10.1080/03610730490484399

Bourgeois, P., \& Hess, U. (2008). The impact of social context on mimicry. Biological Psychology, 77, 343-352. doi:10.1016/j.biopsycho. 2007.11.008

Cacioppo, J. T., Crites, S. L., Gardner, W. L., \& Berntson, G. G. (1994). Bioelectrical echoes from evaluative categorizations: I. A late positive brain potential that varies as a function of trait negativity and extremity. Journal of Personality and Social Psychology, 67, 115125. doi:10.1037/0022-3514.67.1.115

Caharel, S., Montalan, B., Fromager, E., Bernard, C., Lalonde, R., \& Mohamed, R. (2011). Other-race and inversion effects during the structural encoding stage of face processing in a race categorization task: An event-related brain potential study. International Journal of Psychophysiology, 79, 266-271. doi:10.1016/j.ijpsycho.2010.10.018

Cuthbert, B. N., Schupp, H. T., Bradley, M. M., Birbaumer, N., \& Lang, P. J. (2000). Brain potentials in affective picture processing: Covariation with autonomic arousal and affective report. Biological Psychology, 52, 95-111. doi:10.1016/S0301-0511(99)00044-7

Czerwon, B., Lüttke, S., \& Werheid, K. (2011). Age differences in valence judgments of emotional faces: The influence of personality traits and current mood. Experimental Aging Research, 37, 503515. doi:10.1080/0361073X.2011.619468
Donchin, E., \& Coles, M. G. (1988). Is the P300 component a manifestation of context updating? Behavioral and Brain Sciences, 11, 357374. doi:10.1017/S0140525X00058027

Duval, E. R., Moser, J. S., Huppert, J. D., \& Simons, R. F. (2013). What's in a face? The late positive potential reflects the level of facial affect expression. Journal of Psychophysiology, 27, 27-38. doi:10.1027/ 0269-8803/a000083

Ebner, N. C., \& Johnson, M. K. (2009). Young and older emotional faces: Are there age group differences in expression identification and memory? Emotion, 9, 329-339. doi:10.1037/a0015179

Ebner, N. C., \& Johnson, M. K. (2010). Age-group differences in interference from young and older emotional faces. Cognition \& Emotion, 24, 1095-1116. doi:10.1080/02699930903128395

Ebner, N. C., Riediger, M., \& Lindenberger, U. (2010). FACES- A database of facial expressions in young, middle-aged, and older women and men: Development and validation. Behavior Research Methods, 42, 351-362. doi:10.3758/BRM.42.1.351

Ebner, N. C., He, Y., Fichtenholtz, H. M., McCarthy, G., \& Johnson, M. K. (2011). Electrophysiological correlates of processing faces of younger and older individuals. Social Cognitive and Affective Neuroscience, 6, 526-535. doi:10.1093/Scan/Nsq074

Ebner, N. C., He, Y., \& Johnson, M. K. (2011). Age and emotion affect how we look at a face: Visual scan patterns differ for own-age versus other-age emotional faces. Cognition \& Emotion, 25(6), 983-997. doi:10.1080/02699931.2010.540817

Ebner, N. C., Johnson, M. K., \& Fischer, H. (2012). Neural mechanisms of reading facial emotions in young and older adults. Frontiers in Psychology, 3, 223. doi:10.3389/fpsyg.2012.00223

Ebner, N. C., Johnson, M. R., Rieckmann, A., Durbin, K. A., Johnson, M. K., \& Fischer, H. (2013). Processing own-age vs. other-age faces: Neuro-behavioral correlates and effects of emotion. NeuroImage, 78, 363-371. doi:10.1016/j.neuroimage.2013.04.029

Eimer, M. (2011). The face-sensitive N170 component of the eventrelated brain potential. In A. J. Calder, G. Rhodes, M. H. Johnson, \& J. V. Haxby (Eds.), The Oxford handbook of face perception (pp. 329-344). Oxford: Oxford University Press.

Eimer, M., \& Holmes, A. (2002). An ERP study on the time course of emotional face processing. NeuroReport, 13, 427-431. doi:10.1097/ 00001756-200203250-00013

Eimer, M., \& Holmes, A. (2007). Event-related brain potential correlates of emotional face processing. Neuropsychologia, 45, 15-31. doi:10.1016/j.neuropsychologia.2006.04.022

Eimer, M., Holmes, A., \& McGlone, F. P. (2003). The role of spatial attention in the processing of facial expression: An ERP study of rapid brain responses to six basic emotions. Cognitive, Affective, \& Behavioral Neuroscience, 3, 97-110. doi:10.3758/CABN.3.2.97

Elfenbein, H. A., \& Ambady, N. (2002). On the universality and cultural specificity of emotion recognition: A meta-analysis. Psychological Bulletin, 128, 203-235. doi:10.1037/0033-2909.128.2.203

Fölster, M., Hess, U., Hühnel, I., \& Werheid, K. (2015). Age-related response bias in the decoding of sad facial expressions. Behavioral Sciences, 5, 443-460. doi:10.3390/bs5040443

Gajewski, P. D., Schlegel, K., \& Stoerig, P. (2008). Effects of human race and face inversion on the N170: A cross-race study. Journal of Psychophysiology, 22, 157-165. doi:10.1027/0269-8803.22.4.157

Gao, L., Xu, J., Zhang, B., Zhao, L., Harel, A., \& Bentin, S. (2009). Aging effects on early-stage face perception: An ERP study. Psychophysiology, 46, 970-983. doi:10.1111/j.1469-8986.2009.00853.x

Harrison, V., \& Hole, G. J. (2009). Evidence for a contact-based explanation of the own-age bias in face recognition. Psychonomic Bulletin \& Review, 16, 264-269. doi:10.3758/PBR.16.2.264

He, Y., Johnson, M. K., Dovidio, J. F., \& McCarthy, G. (2009). The relation between race-related implicit associations and scalprecorded neural activity evoked by faces from different races. Social Neuroscience, 4, 426-442. doi:10.1080/174709109029 49184 
Herbert, C., Kissler, J., Junghöfer, M., Peyk, P., \& Rockstroh, B. (2006). Processing of emotional adjectives: Evidence from startle EMG and ERPs. Psychophysiology, 43, 197-206. doi:10.1111/j.1469-8986. 2006.00385.x

Herrmann, M. J., Schreppel, T., Jäger, D., Koehler, S., Ehlis, A. C., \& Fallgatter, A. J. (2007). The other-race effect for face perception: An event-related potential study. Journal of Neural Transmission, 114, 951-957. doi:10.1007/s00702-007-0624-9

Holmes, A., Vuilleumier, P., \& Eimer, M. (2003). The processing of emotional facial expression is gated by spatial attention: Evidence from event-related brain potentials. Cognitive Brain Research, 16, 174-184. doi:10.1016/S0926-6410(02)00268-9

Horn, W. (1983). Leistungsprüfsystem: L-P-S (2nd ed.). Göttingen: Hogrefe.

Hugenberg, K., Young, S. G., Bernstein, M. J., \& Sacco, D. F. (2010). The categorization-individuation model: An integrative account of the other-race recognition deficit. Psychological Review, 117, 11681187. doi:10.1037/A0020463

Hühnel, I., Fölster, M., Werheid, K., \& Hess, U. (2014). Empathic reactions of younger and older adults: No age related decline in affective responding. Journal of Experimental Social Psychology, 50, 136143. doi:10.1016/j.jesp.2013.09.011

Kayser, J., Tenke, C., Nordby, H., Hammerborg, D. A. G., Hugdahl, K., \& Erdmann, G. (1997). Event-related potential (ERP) asymmetries to emotional stimuli in a visual half-field paradigm. Psychophysiology, 34, 414 426. doi:10.1111/j.1469-8986.1997.tb02385.x

Kloth, N., Damm, M., Schweinberger, S. R., \& Wiese, H. (2015). Aging affects sex categorization of male and female faces in opposite ways. Acta Psychologica, 158, 78-86. doi:10.1016/j. actpsy.2015.04.005

Krombholz, A., Schaefer, F., \& Boucsein, W. (2007). Modification of N170 by different emotional expression of schematic faces. Biological Psychology, 76, 156-162. doi:10.1016/j.biopsycho.2007. 07.004

Luo, W., Feng, W., He, W., Wang, N. Y., \& Luo, Y. J. (2010). Three stages of facial expression processing: ERP study with rapid serial visual presentation. Neurolmage, 49, 1857-1867. doi:10.1016/j.neuroimage. 2009.09.018

Malatesta, C. Z., Izard, C. E., Culver, C., \& Nicolich, M. (1987). Emotion communication skills in young, middle-aged, an older women. Psychology and Aging, 2, 193-203. doi:10.1037/08827974.2.2.193

Murphy, N. A., Lehrfeld, J. M., \& Isaacowitz, D. M. (2010). Recognition of posed and spontaneous dynamic smiles in young and older adults. Psychology and Aging, 25, 811-821. doi:10.1037/a0019888

Neumann, M. F., End, A., Luttmann, S., Schweinberger, S. R., \& Wiese, H. (2015). The own-age bias in face memory is unrelated to differences in attention-Evidence from event-related potentials. Cognitive, Affective, \& Behavioral Neuroscience, 15, 180-194. doi:10.3758/ s13415-014-0306-7

Recio, G., Schacht, A., \& Sommer, W. (2014). Recognizing dynamic facial expressions of emotion: Specificity and intensity effects in event-related brain potentials. Biological Psychology, 96, 111-125. doi:10.1016/j.biopsycho.2013.12.003

Rellecke, J., Palazova, M., Sommer, W., \& Schacht, A. (2011). On the automaticity of emotion processing in words and faces: Eventrelated brain potentials evidence from a superficial task. Brain and Cognition, 77, 23-32. doi:10.1016/j.bandc.2011.07.001

Rellecke, J., Sommer, W., \& Schacht, A. (2012). Does processing of emotional facial expressions depend on intention? Time-resolved evidence from event-related brain potentials. Biological Psychology, 90, 23-32. doi:10.1016/j.biopsycho.2012.02.002

Rhodes, M. G., \& Anastasi, J. S. (2012). The own-age bias in face recognition: A meta-analytic and theoretical review. Psychological Bulletin, 138, 146-174. doi:10.1037/a0025750
Schacht, A., \& Sommer, W. (2009). Time course and task dependence of emotion effects in word processing. Cognitive, Affective, \& Behavioral Neuroscience, 9, 28-43. doi:10.3758/CABN.9.1.28

Schmidt, K.-H., \& Metzler, P. (1992). Wortschatztest: WST. Göttingen: Beltz Test.

Schubert, T. W., \& Otten, S. (2002). Overlap of self, ingroup, and outgroup: Pictorial measures of self-categorization. Self and Identity, $1,353-376$.

Schupp, H. T., Cuthbert, B. N., Bradley, M. M., Cacioppo, J. T., Ito, T., \& Lang, P. J. (2000). Affective picture processing: The late positive potential is modulated by motivational relevance. Psychophysiology, 37, 257-261. doi:10.1111/1469-8986.3720257

Schupp, H. T., Öhman, A., Junghofer, M., Weike, A. I., Stockburger, J., \& Hamm, A. O. (2004). The facilitated processing of threatening faces: An ERP analysis. Emotion, 4, 189-200. doi:10.1037/1528-3542.4. 2.189

Schupp, H. T., Stockburger, J., Codispoti, M., Junghöfer, M., Weike, A. I., \& Hamm, A. O. (2007). Selective visual attention to emotion. Journal of Neuroscience, 27, 1082-1089. doi:10.1523/JNEUROSCI.322306.2007

Stahl, J., Wiese, H., \& Schweinberger, S. R. (2008). Expertise and ownrace bias in face processing: An event-related potential study. NeuroReport, 19, 583-587. doi:10.1097/WNR.0b013e3282f97b4d

Stahl, J., Wiese, H., \& Schweinberger, S. R. (2010). Learning task affects ERP-correlates of the own-race bias, but not recognition memory performance. Neuropsychologia, 48, 2027-2040. doi:10.1016/j. neuropsychologia.2010.03.024

Tzeng, O. C., \& Jackson, J. W. (1994). Effects of contact, conflict, and social identity on interethnic group hostilities. International Journal of Intercultural Relations, 18, 259-276. doi:10.1016/0147-1767(94) 90031-0

van der Schalk, J., Fischer, A., Doosje, B., Wigboldus, D., Hawk, S., Rotteveel, M., \& Hess, U. (2011). Convergent and divergent responses to emotional displays of ingroup and outgroup. Emotion, 11, 286-298. doi:10.1037/a0022582

Walker, P. M., Silvert, L., Hewstone, M., \& Nobre, A. C. (2007). Social contact and other-race face processing in the human brain. Social Cognitive and Affective Neuroscience, 3, 16-25. doi:10.1093/scan/ $\mathrm{nsm} 035$

Wiese, H. (2012). The role of age and ethnic group in face recognition memory: ERP evidence from a combined own-age and own-race bias study. Biological Psychology, 89, 137-147. doi:10.1016/j. biopsycho.2011.10.002

Wiese, H., Schweinberger, S. R., \& Hansen, K. (2008). The age of the beholder: ERP evidence of an own-age bias in face memory. Neuropsychologia, 46, 2973-2985. doi:10.1016/j.neuropsychologia. 2008.06 .007

Wiese, H., Komes, J., \& Schweinberger, S. R. (2012). Daily-life contact affects the own-age bias and neural correlates of face memory in elderly participants. Neuropsychologia, 50, 3496-3508. doi:10. 1016/j.neuropsychologia.2012.09.022

Wiese, H., Komes, J., \& Schweinberger, S. R. (2013). Ageing faces in ageing minds: A review on the own-age bias in face recognition. Visual Cognition, 21, 1337-1363. doi:10.1080/13506285.2013. 823139

Wiese, H., Wolff, N., Steffens, M. C., \& Schweinberger, S. R. (2013). How experience shapes memory for faces: An event-related potential study on the own-age bias. Biological Psychology, 94, 369-379. doi:10.1016/j.biopsycho.2013.07.001

Wiese, H., Kaufmann, J. M., \& Schweinberger, S. R. (2014). The neural signature of the own-race bias: Evidence from event-related potentials. Cerebral Cortex, 24, 826-835. doi:10.1093/cercor/bhs369

Wolff, N., Wiese, H., \& Schweinberger, S. R. (2012). Face recognition memory across the adult life span: Event-related potential evidence from the own-age bias. Psychology and Aging, 27, 1066-1081. doi: $10.1037 / \mathrm{a} 0029112$ 
Wolff, N., Kemter, K., Schweinberger, S. R., \& Wiese, H. (2014). What drives social in-group biases in face recognition memory? ERP evidence from the own-gender bias. Social Cognitive and Affective Neuroscience, 9, 580-590. doi:10.1093/scan/nst024

Wright, C. I., Negreira, A., Gold, A. L., Britton, J. C., Williams, D., \& Barrett, L. F. (2008). Neural correlates of novelty and face-age effects in young and elderly adults. NeuroImage, 42, 956-968. doi:10.1016/j.neuroimage.2008.05.015

Young, S. G., \& Hugenberg, K. (2010). Mere social categorization modulates identification of facial expressions of emotion. Journal of Personality and Social Psychology, 99, 964-977. doi:10.1037/ a0020400 